\title{
Biofeedback and Anger Management: A Literature Review
}

\author{
Heidi Hillman* and Charles J. Chapman \\ Eastern Washington University, Cheney, Washington, USA
}

\begin{abstract}
The purpose of this article was to systematically review the literature on the effects of biofeedback therapy on anger. Biofeedback methods are shown to be effective in the treatment of a number of health conditions; however, a systematic review of biofeedback therapies on anger management has yet to be conducted. Results of the literature review show that little attention was given to anger over the years in comparison to other health and emotional conditions. Research is needed to determine whether biofeedback is an efficacious treatment for emotional regulation.
\end{abstract}

Keywords: biofeedback; anger; emotion regulation

Citation: Hillman, H., \& Chapman, C. J. (2018). Biofeedback and anger management: A literature review. NeuroRegulation, 5(1), 43-49. http://dx.doi.org/10.15540/nr.5.1.43

*Address correspondence to: Heidi Hillman, Department of Edited by:

Psychology, Eastern Washington University, 135 Martin Hall, Rex L. Cannon, PhD, Knoxville Neurofeedback Group, Knoxville, Cheney, WA 99004, USA. Email: hhillman@ewu.edu

Tennessee, USA

Copyright: ( 2018. Hillman and Chapman. This is an Open Access article distributed under the terms of the Creative Commons Attribution License (CC-BY).

Reviewed by:

Rex L. Cannon, PhD, Knoxville Neurofeedback Group, Knoxville, Tennessee, USA

Randall Lyle, PhD, Mount Mercy University, Cedar Rapids, lowa, USA

Anger is an internal state involving various degrees of, and interactions between, physiological, affective, cognitive, and verbal components (Sharkin, 1988). Anger is a naturally occurring emotion expressed on a continuum; however, over time pent up anger can become expressed in ways that become problematic such as assault, violence, and property damage (e.g., Levey, 1990; Maiuro, Cahn, Vitaliano, Wagner, \& Zegree, 1988). Because anger is often accompanied by other negative behaviors-such as aggression, hostility, and health issues-it is important to explore anger as an independent outcome. Del Vecchio and O'Leary (2004) point out that the concept of anger is considered distinct from the concepts of hostility, aggression, and violence and therefore merits separate analysis. Patients with anger issues often display problems with selfregulation that interfere with adaptive functioning (Berenbaum, Raghavan, Le, Vernon, \& Gomez, 2003). One way to teach individuals how to effectively manage their anger is through biofeedback.

Biofeedback-a term for any intervention that uses medical equipment to monitor body function that is otherwise outside of our awareness-is a mind- body technique to help people learn to better control involuntary physiological responses. However, biofeedback is not a passive "treatment," such as electrotherapy or ultrasound; instead, it is a noninvasive method where a person actively learns how to control bodily processes. The feedback helps a person focus on making subtle bodily changes such as recognizing when muscles are tense and relaxing those muscles or focusing on heart rate and breathing patterns.

In 2008, the Association for Applied Psychophysiology and Biofeedback (AAPB), the Biofeedback Certification International Alliance (BCIA), and the International Society for Neurofeedback and Research (ISNR) agreed upon a working definition for biofeedback:

Biofeedback is a process enabling an individual to learn how to change physiological activity for the purposes of improving health and performance. Precise instruments measure physiological activity such as brain waves, heart function, breathing, muscle activity, and skin temperature. These instruments rapidly and accurately provide 'feedback' information to the 
user. The presentation of this informationoften in conjunction with changes in thinking, emotion, and behavior-supports desired physiological changes. Over time, these changes can endure without the use of an instrument.

In the years since 1990, as shown in Figure 1, the popularity of biofeedback has exploded, both in the literature and in practice. Biofeedback training is offered in physical therapy clinics, medical centers, universities, and hospitals (AskMayoExpert, 2015). In addition, a growing number of biofeedback devices are being marketed for home use (Mayo Clinic, 2016). Only a few articles were published between 1960 and 1989 (e.g., Baglis-Smith, Smith, Rose, \& Newman, 1989; Corder, Whiteside, \& Haizlip, 1986; Fishbain et al., 1988; Maiuro \& Eberle, 1989). In the 1990s, 122 articles were published (e.g., Carlson, Singelis, \& Chemtob, 1997; Engel \& Rapoff, 1990; Lundervold \& Poppen, 1995; Nicholson \& Blanchard, 1993), and between 2000 and 2009, 744 articles were published (e.g., Hawkins \& Hart, 2003; McLay \& Spira, 2009; Sarafino \& Goehring, 2000; Vaschillo, Vaschillo, \& Lehrer, 2006). From 2010 to April 2017, 473 articles on biofeedback were published (e.g., Faedda et al., 2016; Glombiewski, Hartwich-Tersek, \& Rief, 2010; Prinsloo, Derman, Lambert, \& Rauch, 2013).

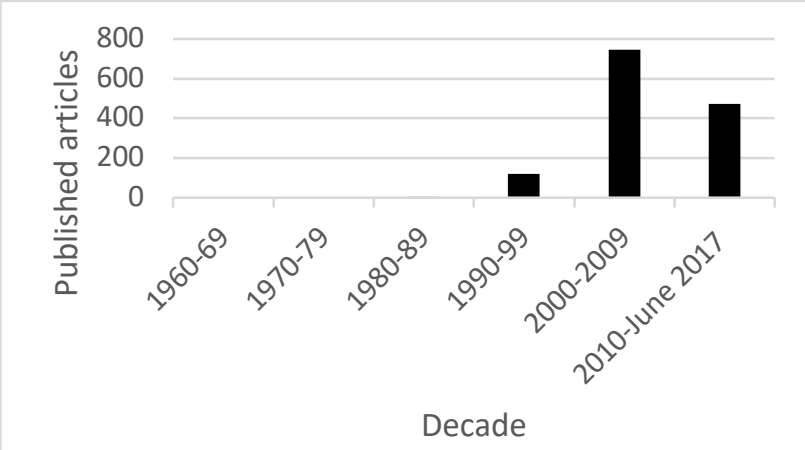

Figure 1. Number of published biofeedback articles by decade, between years of 1960-2017.

Over the years, biofeedback has been shown to have various levels of efficacy for over 40 health conditions including, but not limited to, anxiety, ADHD, headache, insomnia, and chronic pain (e.g., Frank, Khorshid, Kiffer, Moravec, \& McKee, 2010). Frank et al. (2010) conducted a literature review of the effectiveness of biofeedback on various health conditions, and they found that the majority of the published studies were effective and modifying the target behavior. See Table 1 for the list of the health conditions. However, after reading Frank et al. (2010) the authors of this article questioned whether biofeedback had been used to increase emotional regulation, specifically decreasing anger. The purpose of this article was to conduct a review of the biofeedback literature examining whether biofeedback was used in reducing feelings of anger.

\section{Table 1}

Health conditions addressed with biofeedback.

\begin{tabular}{|c|c|c|}
\hline Condition & $\begin{array}{l}\text { Number of } \\
\text { Articles }\end{array}$ & Effectiveness \\
\hline Alcoholism & 47 & $\begin{array}{l}\text { Probably } \\
\text { efficacious }\end{array}$ \\
\hline Anxiety & 667 & Efficacious \\
\hline $\begin{array}{l}\text { Attention Deficit } \\
\text { Hyperactivity } \\
\text { Disorder/ADHD }\end{array}$ & 258 & Efficacious \\
\hline Chronic Pain & 454 & Efficacious \\
\hline Constipation (adult) & 12 & Efficacious \\
\hline Diabetes Mellitus & 64 & $\begin{array}{l}\text { Probably } \\
\text { efficacious }\end{array}$ \\
\hline Epilepsy & 112 & Efficacious \\
\hline Fecal Incontinence & 29 & $\begin{array}{l}\text { Probably } \\
\text { efficacious }\end{array}$ \\
\hline Headache (adult) & 92 & Efficacious \\
\hline Headache (pediatric) & 78 & $\begin{array}{l}\text { Probably } \\
\text { efficacious }\end{array}$ \\
\hline Hypertension & 182 & Efficacious \\
\hline Insomnia & 115 & $\begin{array}{l}\text { Probably } \\
\text { efficacious }\end{array}$ \\
\hline Motion Sickness & 16 & Efficacious \\
\hline Raynaud's Disease & 4 & Efficacious \\
\hline Substance Abuse & 100 & $\begin{array}{l}\text { Probably } \\
\text { efficacious }\end{array}$ \\
\hline $\begin{array}{l}\text { Temporomandibular } \\
\text { Disorder }\end{array}$ & 41 & Efficacious \\
\hline Traumatic Brain Injury & 79 & $\begin{array}{l}\text { Probably } \\
\text { efficacious }\end{array}$ \\
\hline $\begin{array}{l}\text { Urinary Incontinence } \\
\text { (female) }\end{array}$ & 41 & Efficacious \\
\hline $\begin{array}{l}\text { Urinary Incontinence } \\
\text { (male) }\end{array}$ & 24 & $\begin{array}{l}\text { Probably } \\
\text { efficacious }\end{array}$ \\
\hline Vulvar Vestibulitis & 16 & $\begin{array}{l}\text { Probably } \\
\text { efficacious }\end{array}$ \\
\hline
\end{tabular}




\section{Method}

The information retrieval strategy included a search of Psychology journals between 1900 and September 2017, using the Educational Resources Information Center (ERIC) and PsychINFO databases. Search parameters included using a combination of the following descriptors: biofeedback, biofeedback and anger, and biofeedback and anger management. From the initial search 7,347 articles were found. Studies were eligible for inclusion in the review if the words biofeedback and anger were in the title or the abstract of the paper. Of the 7,347 articles, only 48 met these criteria. Two reviewers independently reviewed each of the 48 articles to determine inclusion eligibility based on the following criteria: (1) the words biofeedback, anger, or anger management had to be in the abstract; (2) the study used biofeedback as a treatment; and (3) the study assessed the effectiveness of biofeedback on anger or anger management. Five articles were identified as meeting the criteria of using biofeedback as a treatment protocol specifically focusing on anger.

\section{Results}

\section{Brief Overview of Studies}

A breakdown of the five articles can be seen in Table 2. The five studies included in the analysis were published between 1982 and 2017, with two of the five studies published in 1982 and 1986 and three articles published after 2012. Two of the studies used a pre-post intervention design, and three studies used a variation of the case study design. Experimental control was demonstrated in one study (Kahn, Ducharme, Rotenberg, \& Gonzalez-Heydrich, 2013) through the use of an experimental and control group. Social validity was measured in one study (Kahn et al., 2013). Length of intervention ranged from 5 days to 5 weeks for four of the articles and 56 sessions over the course of one year for one of the articles (Golden \& Consorte, 1982).

\section{Table 2}

Characteristics of the five articles that used biofeedback with emotional regulation.

\begin{tabular}{|c|c|c|c|c|c|}
\hline & Chapman (2017) & $\begin{array}{l}\text { Corder, } \\
\text { Whteside, \& } \\
\text { Haizlip (1986) }\end{array}$ & $\begin{array}{l}\text { Ducharme et al. } \\
\text { (2012) }\end{array}$ & $\begin{array}{l}\text { Golden \& } \\
\text { Consorte (1982) }\end{array}$ & $\begin{array}{l}\text { Kahn, Ducharme, } \\
\text { Rotenberg, \& } \\
\text { Gonzalez- } \\
\text { Heydrich (2013) }\end{array}$ \\
\hline Participants & 1 Adult & $\begin{array}{l}13 \text { adolescents } \\
\text { (range 13-18 } \\
\text { years old) }\end{array}$ & 16 years old & $\begin{array}{l}4 \text { mildly retarded } \\
\text { adults (19, } 30,36, \\
\text { and } 54 \text { years old) }\end{array}$ & $\begin{array}{l}38 \text { (range 9-17 } \\
\text { years old) }\end{array}$ \\
\hline Setting & $\begin{array}{l}\text { Two settings: } \\
\text { Home } \\
\text { Public }\end{array}$ & $\begin{array}{l}\text { State hospital, } \\
\text { adolescence } \\
\text { inpatient ward }\end{array}$ & $\begin{array}{l}\text { Inpatient psychiatric } \\
\text { unit }\end{array}$ & Not stated & $\begin{array}{l}\text { Inpatient } \\
\text { psychiatric unit }\end{array}$ \\
\hline Treatment & $\begin{array}{l}\text { Biofeedback, using } \\
\text { the emWave } 2 \\
\text { portable } \\
\text { biofeedback unit }\end{array}$ & $\begin{array}{l}\text { Biofeedback, } \\
\text { cognitive skills, } \\
\text { and relaxation } \\
\text { training program }\end{array}$ & $\begin{array}{l}\text { RAGE-Control } \\
\text { videogame, loosely } \\
\text { based on an arcade } \\
\text { game. Players control } \\
\text { their physiological } \\
\text { arousal while } \\
\text { responding to the } \\
\text { stress presented by } \\
\text { the challenges of the } \\
\text { game. }\end{array}$ & $\begin{array}{l}\text { Rational emotive } \\
\text { therapy, } \\
\text { biofeedback } \\
\text { assisted relaxation, } \\
\text { behavioral } \\
\text { treatment. } \\
\text { Biofeedback } \\
\text { apparatus was } \\
\text { used. }\end{array}$ & $\begin{array}{l}\text { RAGE-Control } \\
\text { videogame, a } \\
\text { biofeedback } \\
\text { strategy }\end{array}$ \\
\hline Duration & $\begin{array}{l}5 \text { weeks; two } \\
\text { interventions/day }\end{array}$ & $\begin{array}{l}9 \text { weeks, weekly } \\
\text { training sessions } \\
\text { of } 1 \text { hour }\end{array}$ & $\begin{array}{l}5 \text { days, } 1 \text { hour each } \\
\text { day }\end{array}$ & $\begin{array}{l}56 \text { sessions over } 1 \\
\text { year for } 30 \text {-year-old }\end{array}$ & $\begin{array}{l}5 \text { days, } 1 \text { hour } \\
\text { each day }\end{array}$ \\
\hline $\begin{array}{l}\text { Target } \\
\text { behavior }\end{array}$ & Anger and temper & $\begin{array}{l}\text { Temper and } \\
\text { impulsive behavior }\end{array}$ & Anger regulation & $\begin{array}{l}\text { Self-control of } \\
\text { anger }\end{array}$ & Anger regulation \\
\hline
\end{tabular}




\section{Table 2}

Characteristics of the five articles that used biofeedback with emotional regulation.

$\begin{array}{lllll}\text { Chapman (2017) } & \begin{array}{l}\text { Corder, } \\ \text { Whteside, \& } \\ \text { Haizlip (1986) }\end{array} & \begin{array}{l}\text { Ducharme et al. } \\ \text { (2012) }\end{array} & \begin{array}{l}\text { Golden \& } \\ \text { Consorte (1982) }\end{array} & \begin{array}{l}\text { Kahn, Ducharme } \\ \text { Rotenberg, \& } \\ \text { Gonzalez- } \\ \text { Heydrich (2013) }\end{array}\end{array}$

Behavior

measured in

frequency $(\mathrm{a}$

decrease from a

high of 13 anger events each of the second and third weeks to 2 during the fifth week) and intensity (dropping from 3 each of the first 2 weeks to 0.6667 during the last week).
Client's anger

No data anecdotal reports from aides and teachers saying that impulsive behavior of participants decreased. decreased from baseline score of 59 out of a possible score of 60 (indicates very high levels of anger) to post treatment score of 11. These data indicate a large drop in her reported level of anger and aggression.
Only one

participant used biofeedback. His results showed his anger outbursts decreased to two minor outbursts by the end of his treatment. However, authors do not state what his baseline level was.

\author{
Treatment group \\ had statistically \\ significant \\ reduction in anger \\ intensity
}

\section{Review of Included Studies}

Chapman (2017) used a case study design to study the effects of biofeedback therapy on a 54-year-old male who indicated lifelong high-intensity anger issues and extreme difficulty controlling his temper. Prior to the study the participant attended individual counseling. During the study the participant attended counseling along with biofeedback intervention using a portable biofeedback unit. Biofeedback treatments consisted of participant putting on the biofeedback unit and controlling physiological responses based on feedback from biofeedback apparatus. Each treatment was approximately three minutes long and conducted twice daily. During a 12-day baseline the participant experienced 32 anger events. During a 29-day biofeedback intervention, the participant's number of anger events decreased to 10 during the first 7 days and two anger events during the last 7 days of the intervention.

Corder, Whiteside, and Haizlip (1986) conducted a pilot study to study the effects of a multimodal treatment approach consisting of biofeedback, cognitive skills, relaxation training, and individual therapy on temper and impulsive behavior of 13 adolescents residing in a state hospital adolescent treatment unit. The intervention consisted of 1-hour weekly training sessions over a 9-week period. Each session included practice in cognitive training, recognizing behavioral cues leading to aggression and relaxation techniques using biofeedback. Each session ended with the assignment of homework that consisted of practicing the tasks introduced in the session. Results were gathered through anecdotal reports from hospital unit aides and teachers working with the adolescents. Unit staff and teachers reported positive changes in increased impulse control of the participants and a decrease in the number of time-outs participants received during the pilot study. A number of teachers reported the ability to diffuse crisis situations in the participants by simply reminding the participants to use their relaxation techniques. Even though Corder et al. (1986) reported the multimodal treatment approach was successful at reducing temper and impulsive behavior, they did not report any pre- and posttreatment data. Hence, it is impossible for the authors of this article to arrive at their own conclusions about whether the treatment was, in fact, efficacious.

Ducharme et al. (2012) described the treatment of a 16-year-old girl who received anger control therapy (ACT) with an active biofeedback video game "RAGE-Control" intervention. The intervention was delivered as daily counseling sessions and ended with playing RAGE-Control over 5 consecutive days. Using the State Trait Anger Expression Inventory for Children and Adolescents (STAXI-CA) where the maximum possible score is 60 , the participant's feelings of anger decreased from a baseline score of 30 to a posttreatment score of 11 . Likewise, the participant's anger intensity reduced from a baseline score of 29 to posttreatment score of 19.

Golden and Consorte (1982) studied the effects of a cognitive-behavioral approach on reducing chronic anger behaviors of four adults with an intellectual disability. The treatment consisted of cognitive- 
behavioral therapy and biofeedback-relaxation techniques. However, the treatment components varied for each of the four participants; only two participants received biofeedback. Since the treatment was not identical in all four cases and only two participants received biofeedback as part of their treatment, we are only discussing the data on those two participants. One participant was a 30 -year-old male whose treatment consisted of biofeedbackassisted relaxation-using a portable biofeedback device, relaxation training, coping statements and imagery, assertiveness training, Rational Emotive Behavior Therapy (REBT), and behavioral rehearsal. The participant received 56 sessions over the course of 1 year, and during this time had two minor angry outbursts. The second participant was a 36year-old woman whose treatment consisted of biofeedback-assisted relaxation, a stress-inoculation training, and behavioral rehearsal. The participant received 24 sessions; however, Golden and Consorte (1982) do not state the length of time the sessions occurred. The results demonstrate that at least some individuals with limited intellectual capacity can learn to regulate anger outbursts.

Kahn, Ducharme, Rotenberg, and GonzalezHeydrich (2013) compared an experimental group (18 children ranging between 9 and 17 years of age) to a control group (19 children ranging between 9 and 17 years of age) to evaluate the effects of a treatment consisting of anger control therapy (ACT) with an active biofeedback video game called "RAGE-Control" on increasing emotional regulation skills and reducing feelings of anger. Treatment consisted of therapy and game playing for 5 consecutive days. The authors measured pre- and postintervention levels of anger using the State and Trait Anger Expression Inventory for Children and Adolescents (STAXI-CA). Compared with the control group, children in the experimental group showed statistically significant decreases in frequency of feeling angry and a decline in anger intensity. However, Kahn et al. (2013) did not report baseline or treatment data. Hence, it is impossible for the authors of this article to make their own conclusions on whether there really was a significant decrease in anger and intensity among the participants. In addition to measuring feelings of anger and anger intensity, Kahn et al. (2013) also compared the amount of time each participant stayed below a specific heart rate threshold. Those children in the experimental group had a statistically significant improvement in controlling their heart rate during game play. The authors inferred lower heart rate to higher emotional regulation.

\section{Discussion}

While these five articles demonstrate the potential effectiveness of biofeedback in anger management, there are important limitations to consider. First, all but two articles outlined the effectiveness of a biofeedback intervention with only one participant. For example, Golden and Consorte (1982) used four participants in their study but only one participant used biofeedback as a treatment. It is difficult to generalize results to the wider population of people with anger issues. More research is needed focusing on more participants before stating biofeedback is an effective way to regulate emotions.

Second, all five studies used biofeedback in addition to other treatments-such as relaxation, group or individual therapy, and cognitive-behavioral therapy. When biofeedback treatments contain several treatment components, it is difficult to determine which treatments resulted in reduction in anger episodes. More research isolating biofeedback components is needed to evaluate the effectiveness of biofeedback on reducing anger in people. Conducting research where biofeedback is the only treatment variable may allow researchers to tease out effective components contributing to anger reduction.

Third, only one study (Kahn et al., 2013) demonstrated experimental control through the use of a control and experimental group. The other four articles used a variation of case study research, which is not a strong experimental design when considering effectiveness of a treatment. More research using stronger experimental methods is needed to demonstrate that biofeedback is in fact the variable-and not other confounding variablescausing changes in emotional regulation.

Fourth, anger management is not a behavior that only occurs in a treatment setting, hence researchers need to assess generalization effects of biofeedback treatments in reducing anger across various settings. Success of a biofeedback treatment needs to be judged based on the ability of the person to reduce anger in multiple settings. Chapman (2017) was the only study that evaluated the effects of the biofeedback treatment in two different environments-home and public settings. In the home setting, the participant's anger events decreased from three anger events during baseline to zero anger events during the last week of intervention. In the public setting the participant's anger events decreased from 29 events during 
baseline to 8 events during the first week of intervention to 2 events during the last week of intervention. When conducting research-especially with anger management-an important factor to focus on is whether the treatment that was effective in the treatment setting is effective in other, diverse settings. Even though Chapman (2017) evaluated the effects of a biofeedback treatment across two settings, more studies are needed to demonstrate generalizability of biofeedback treatments. More research collecting generalization data is needed to close the gap that exists between demonstrating biofeedback effectively reduces anger in treatment settings and demonstrating that biofeedback generalizes to other environments.

Lastly, none of the five articles provided follow-up data after completion of the treatment. Completing follow-up data collection adds validity to the findings reported during the study. The five articles in our review reported how biofeedback reduced anger, but can the treatment gains maintain over time and, if so, for how long? Collecting data after the completion of the research is as important as collecting data during treatment implementation. More research collecting follow-up data points on anger management is needed to demonstrate not just the effectiveness of biofeedback interventions but also how long the treatment gains last.

While more evidence is needed to support the effectiveness of biofeedback on anger management, the preliminary data and anecdotal reports gathered in the five studies appear to show that biofeedback treatments are promising in reducing anger among adolescents and adults. Despite the limitations discussed above, we highly recommend continued research in the area of anger and using biofeedback to improve patients' quality of life. Biofeedback is less invasive, does not involve drugs, and is potentially less expensive and more effective than other counseling or anger management alternatives (Nordqvist, 2017; Schwartz, 1995). For example, Chapman (2017) reported the participant-after a few hours of training-administered biofeedback by himself. However, there is a need for high-quality studies examining the efficacy of biofeedback on anger specifically.

There are dozens of studies discussing biofeedback and its effect on stress relief, and thousands that address many other health conditions (e.g., Greenspoon \& Olson, 1986, Shellenberger, Turner, Green, \& Cooney, 1986; Wyner, 2015). Only a very few appear to focus on addressing the effects of biofeedback on anger as its own construct. While biofeedback has been used successfully in conjunction with other therapies, it has yet to be determined whether or not it is a viable tool in and of itself. With both the frequency and intensity of anger on the rise in today's society-and given that there is little in the way of published research-further research on the effects of biofeedback on anger management not only seems necessary but is strongly encouraged.

\section{References}

AskMayoExpert. (2015). Biofeeedback. Rochester, MN: Mayo Foundation for Medical Education and Research.

Baigis-Smith, J., Smith, D. A. J., Rose, M., \& Newman, D. K. (1989). Managing urinary incontinence in community-residing elderly persons. The Gerontologist, 29(2), 229-233. http://dx.doi.org/10.1093/geront/29.2.229

Berenbaum, H., Raghavan, C., Le, N. H., Vernon, L. L., \& Gomez, J. J. (2003). A taxonomy of emotional disturbances. Clinical Psychology: Science and Practice, 10(2), 206-226. http://dx.doi.org/ 10.1093/clipsy/bpg011

Carlson, J. G., Singelis, T. M., \& Chemtob, C. M. (1997). Facial EMG responses to combat-related visual stimuli in veterans with and without posttraumatic stress disorder. Applied Psychophysiology and Biofeedback, 22(4), 247-259. http://dx.doi.org/10.1023/A:1022295912624

Chapman, C. J. (2017). Biofeedback intervention for anger management: A case study. NeuroRegulation, 4(2), 95-98. http://dx.doi.org/10.15540/nr.4.2.95

Corder, B. F., Whiteside, R., \& Haizlip, T. (1986). Biofeedback, cognitive training and relaxation techniques as multimodal adjunct therapy for hospitalized adolescents: A pilot study. Adolescence, 21(82), 339-346.

Del Vecchio, T., \& O'Leary, K. D. (2004). Effectiveness of anger treatments for specific anger problems: A meta-analytic review. Clinical Psychological Review, 24(1), 15-34. http://dx.doi.org/10.1016/j.cpr.2003.09.006

Ducharme, P., Wharff, E., Hutchinson, E., Kahn, J., Logan, G., \& Gonzalez-Heydrich, J. (2012). Videogame assisted emotional regulation training: An ACT with RAGE-Control case illustration. Clinical Social Work Journal, 40(1), 75-84. http://dx.doi.org/10.1007/s10615-011-0363-0

Engel, J. M., \& Rapoff, M. A. (1990). Biofeedback-assisted relaxation training for adult and pediatric headache disorders. The Occupational Therapy Journal of Research, 10(5), 283-299. http://dx.doi.org/10.1177 /153944929001000504

Faedda, N., Cerutti, R., Verdecchia, P., Migliorini, D., Arruda, M., \& Guidetti, V. (2016). Behavioral management of headache in children and adolescents. The Journal of Headache and Pain, 17(1), 80. http://dx.doi.org/10.1186/s10194-016-0671-4

Fishbain, D. A., Goldberg, M., Khalil, T. M., Asfour, S. S., AbdelMoty, E., Meager, B. R., ... Rosomoff, H. L. (1988). The utility of electromyographic biofeedback in the treatment of conversion paralysis. The American Journal of Psychiatry, 145(12), 1572-1575. http://dx.doi.org/10.1176 lajp.145.12.1572

Frank, D. L., Khorshid, L., Kiffer, J. F., Moravec, C. S., \& McKee, M. G. (2010). Biofeedback in medicine: Who, when, why and how? Mental Health in Family Medicine, 7(2), 85-91.

Glombiewski, J. A., Hartwich-Tersek, J., \& Rief, W. (2010). Two psychological interventions are effective in severely disabled, chronic back pain patients: A randomised controlled trial. International Journal of Behavioral Medicine, 17(2), 97107. http://dx.doi.org/10.1007/s12529-009-9070-4 
Golden, W. L., \& Consorte, J. (1982). Training mildly retarded individuals to control their anger through the use of cognitivebehavior therapy techniques. Journal of Contemporary Psychotherapy, 13(2), 182-187. http://dx.doi.org/10.1007 /BF00946355

Greenspoon, J., \& Olson, J. (1986). Stress management and biofeedback. Clinical Biofeedback \& Health: An International Journal, 9(2), 65-80.

Hawkins, R. S., \& Hart, A. D. (2003). The use of thermal biofeedback in the treatment of pain associated with endometriosis: Preliminary findings. Applied Psychophysiology and Biofeedback, 28(4), 279-289. http://dx.doi.org/10.1023/A:1027378825194

Kahn, J., Ducharme, P., Rotenberg, A., \& Gonzalez-Heydrich, J. (2013). "Rage-Control": A game to build emotional strength. Games for Health Journal, 2(1), 53-57. http://dx.doi.org /10.1089/g4h.2013.0007

Levey, S., \& Howells, K. (1990). Anger and its management. Journal of Forensic Psychiatry, 1, 305-327. http://dx.doi.org/10.1080/09585189008408480

Lundervold, D. A., \& Poppen, R. (1995). Biobehavioral rehabilitation for older adults with essential tremor. The Gerontologist, 35(4), 556-559.

Maiuro, R. D., Cahn, T. S., Vitaliano, P. P., Wagner, B. C., \& Zegree, J. B. (1988). Anger, hostility, and depression in domestically violent versus generally assaultive men and nonviolent control subjects. Journal of Consulting and Clinical Psychology, 56(1), 17-23. http://dx.doi.org/10.1037/0022006X.56.1.17

Maiuro, R. D., \& Eberle, J. A. (1989). New developments in research on aggression: An international report. Violence and Victims, 4(1), 3-15.

Mayo Clinic. (2016). Biofeeedback. Rochester, MN: Mayo Foundation for Medical Education and Research.

McLay, R. N., \& Spira, J. L. (2009). Use of a portable biofeedback device to improve insomnia in a combat zone, a case report. Applied Psychophysiology and Biofeedback, 34(4), 319-321. http://dx.doi.org/10.1007/s10484-009-9104-3

Nicholson, N. L., \& Blanchard, E. B. (1993). A controlled evaluation of behavioral treatment of chronic headache in the elderly. Behavior Therapy, 24(3), 395-408. http://dx.doi.org /10.1016/S0005-7894(05)80213-8

Nordqvist, J. (2017). What is biofeedback therapy and who can benefit? Medical News Today. Retrieved from http://www.medicalnewstoday.com/articles/265802.php

Prinsloo, G. E., Derman, W. E., Lambert, M. I., \& Rauch, H. G. L. (2013). The effect of a single session of short duration biofeedback-induced deep breathing on measures of heart rate variability during laboratory-induced cognitive stress: A pilot study. Applied Psychophysiology and Biofeedback, 38(2), 81-90. http://dx.doi.org/10.1007/s10484013-9210-0

Sarafino, E. P., \& Goehring, P. (2000). Age comparisons in acquiring biofeedback control and success in reducing headache pain. Annals of Behavioral Medicine, 22(1), 10-16. http://dx.doi.org/10.1007/BF02895163

Schwartz, M. S. (1995). Biofeedback: A practitioner's guide (2nd ed.). New York, NY: Guilford Press.

Sharkin, B. S. (1988). The measurement and treatment of client anger in counseling. Journal of Counseling \& Development, 66(8), 361-365. http://dx.doi.org/10.1002/j.15566676.1988.tb00887.x

Shellenberger, R. D., Turner, J., Green, J., \& Cooney, J. B. (1986). Health changes in a biofeedback and stress management program. Clinical Biofeedback \& Health: An International Journal, 9(1), 23-34.

Vaschillo, E. G., Vaschillo, B., \& Lehrer, P. M. (2006). Characteristics of resonance in heart rate variability stimulated by biofeedback. Applied Psychophysiology and Biofeedback, 31(2), 129-142. http://dx.doi.org/10.1007 /s10484-006-9009-3

Wyner, D. R. (2015). Pilot study of a university counseling center stress management program employing mindfulness and compassion-based relaxation training with biofeedback. Biofeedback, 43(3). 121-128. http://dx.doi.org/10.5298/10815937-43.3.01

Received: November 25, 2017

Accepted: December 1, 2017

Published: March 31, 2018 